\title{
Improving heating uniformity of fresh fruit in radio frequency treatments for pest control
}

\author{
S.L. Birla ${ }^{\mathrm{a}}$, S. Wang ${ }^{\mathrm{a}}$, J. Tang ${ }^{\mathrm{a}, *}$, G. Hallman ${ }^{\mathrm{b}}$ \\ ${ }^{a}$ Department of Biological Systems Engineering, Washington State University, 213 L.J. Smith Hall, Pullman, WA 99164-6120, USA \\ ${ }^{\mathrm{b}}$ USADA-ARS, 2413 E. Highway 83, Weslaco, TX 78596, USA
}

Received 20 August 2003; accepted 23 February 2004

\begin{abstract}
Non-uniform heating of fresh fruit caused by variations in radio frequency (RF) fields is a major obstacle in developing postharvest insect control treatments based on RF energy. A fruit mover was developed to evaluate possibilities to improve RF heating uniformity of large fruit, such as oranges and apples, in a $12 \mathrm{~kW}$ batch type RF system. This fruit mover provided a means to rotate and move fruit in water when subjected to RF heating. Parameters for moving and rotating fruit in the mover were selected based on consideration of vortex formation, foaming, damage to the fruit, and volume occupied by the fruit in water. RF heating uniformity of oranges and apples in the mover was assessed using an infrared imaging technique and direct temperature measurement with fiber-optic sensors and thermocouples. The results showed that, with rotation and movement of fruit, temperature uniformity in oranges and apples was significantly improved with less than 2.8 and $3.1{ }^{\circ} \mathrm{C}$ standard deviations, respectively, after an average temperature rise of about $30^{\circ} \mathrm{C}$ in $7.8 \mathrm{~min}$. The fruit mover can be used to develop a treatment protocol for disinfecting fresh fruit and to simulate industrial scale and continuous treatment systems.

(c) 2004 Elsevier B.V. All rights reserved.
\end{abstract}

Keywords: Apple; Fruit mover; Orange; Radio frequency; Temperature uniformity

\section{Introduction}

About $67 \%$ of citrus produced in the world is marketed as fresh, with major citrus-producing countries also acting as major fresh fruit exporters (USDA, 2001). The United States accounts for 53\% world production of grapefruit (Citrus paradise Macfad.) and oranges (Citrus sinensis L. Osbeck). The Mexican (Anastrepha ludens Loew) and Carribbean fruit flies

\footnotetext{
* Corresponding author. Tel.: +1-509-3352140; fax: $+1-509-3352722$.

E-mail address: jtang@mail.wsu.edu (J. Tang).
}

(Anastrepha suspensa Loew) are quarantine pests of citrus fruit as they threaten the entire fresh produce industry because of their broad host ranges (Calkins, 1993). In the USA citrus shipments destined for states such as California, Arizona, and Florida, as well as for export markets including Japan and other Pacific Rim countries, require methyl bromide fumigation to meet import quarantine security requirements. State of Washington is a major producer of fresh apples. Apples exported to Japan are quarantined for codling moth (Cydia pommonella $\mathrm{L}$.) by storing apples in cold storage at $2.2^{\circ} \mathrm{C}$ for 55 days or exposure of methyl bromide fumigation (Hansen et al., 2000). However, 
methyl bromide fumigation often damages the citrus. It is also an ozone depleting chemical and will be restricted or eliminated for most applications by the year 2005 (USEPA, 1998) according to the Montreal Protocol (UNEP, 1992). Thus, development of alternative physical treatments for disinfestation of fresh fruit is urgently needed.

Several alternative methods have been investigated, including ionizing radiation (Burditt, 1982), cold storage (Schiffman-Nadel et al., 1972, 1975), conventional hot air and water heating (Sharp et al., 1991; Shellie et al., 1992; Shellie and Mangan, 1993, 1995, 1998), and radio frequency (RF) treatments (Hallman and Sharp, 1994; Tang et al., 2000; Ikediala et al., 2002; Wang et al., 2001a, 2002) for different fruit and agricultural commodities. Use of irradiation works if insect mortality is not required, but sterility or incomplete development suffice (Hatton et al., 1984). It also requires significant capital investments for special treatment facilities. Cold storage requires lengthy treatment times $\left(\sim 16\right.$ days at $\left.0-2{ }^{\circ} \mathrm{C}\right)$ for disinfestation, and causes chilling injury due to the narrow safety margin for fruit quality. Heat treatments can be an effective control against quarantined pests of certain commodities (Hansen, 1992). Codling moth can be completely killed after a full exposure to temperature of 50 and $52^{\circ} \mathrm{C}$ for 5 and $2 \mathrm{~min}$ respectively (Wang et al., 2002) while fruit flies can be eliminated after similar heat exposure (Gazit et al., 2004). A common difficulty with hot air or water heating methods is the slow rate of heat transfer resulting in hours of treatment time, especially for large fruit (Wang et al., 2001b). For example, Soderstrom et al. (1996) showed that exposure to $39^{\circ} \mathrm{C}$ in air would take about $730 \mathrm{~h}$ to obtain Probit 9 quarantine security (99.996832\% mortality). Prolonged heating may be detrimental to the quality of treated products, causing peel browning, pitting, poor color development and abnormal softening (Lurie, 1998), and may not be practical for industrial applications. New treatments are needed to replace ones that have been lost, are threatened, or have problems. The desire to eliminate these problems and achieve fast and effective thermal processing has resulted in increased interest in using RF energy to control insect pests in commodities.

Radio frequency heating has been studied as a rapid disinfestation treatment (Headlee and Burdette, 1929;
Frings, 1952; Nelson and Payne, 1982), with one of the chief problems being lack of uniform heating (Tang et al., 2000). Recently, treatment protocols have been developed using RF treatments that can effectively control codling moth (Wang et al., 2001a) and navel orangeworm (Wang et al., 2002) in in-shell walnuts without causing quality losses. These studies focus on dry nuts that have higher heat tolerance than fresh fruit. Fresh fruit suffers thermal damage (burn) at the points of contact with the container or with other fruit when heated with RF energy in air. This is the result of overheating caused by a concentration of electric fields around the contact areas because the contact surfaces have the least resistance to RF energy. To avoid fruit-to-fruit contact during RF heating and to make the load more homogeneous to RF fields, a medium that has similar dielectric properties to fruit (Wang et al., 2003) can be selected to fill the void space between the fruit. Dielectric properties influence reflection of electromagnetic waves at interfaces and the attenuation of the wave energy within materials. That in turn determines the amount of energy absorbed and converted into heat. Ikediala et al. (2002) used water as a medium to improve RF heating uniformity in cherries without their movement in the RF field. For larger fruit, such as citrus and apples, heating uniformity is impaired by variations of RF field along the length and width of the exposed area of the container as well as along the height of the water column in the container. Large temperature variations among and within fresh fruit can both reduce the effectiveness of a treatment and cause severe thermal damage to the fruit. Immersing fruit in a medium can solve the problem of contact surface overheating, but will not overcome non-uniform heating caused by varying RF fields in the large fruit and the medium. It is hypothesized that constant movement of fruit in a RF field will improve the heating uniformity of large fruit. Three-dimensional rotation and movement of fruit in a dielectrically matched medium may provide an opportunity for different parts of a fruit to absorb equal amounts of energy in an uneven RF field. The objectives of this study were (1) to develop a laboratory scale fruit mover for assessing the improvement in RF heating uniformity due to movement and spinning of fruit, and (2) to compare the RF heating uniformity of oranges with conventional heating methods such as hot air and hot water. 


\section{Materials and methods}

\subsection{Design considerations for a fruit mover for $R F$ heating}

Non-uniform heating of fruit may be caused by non-uniform RF fields and non-uniform load between the two electrodes in a RF system. Moving and rotating fruit and filling the void space with a medium that has similar dielectric properties (Ikediala et al., 2002; Wang et al., 2003) to that of fruit may improve heating uniformity. Fresh fruit in general float in water, which makes it easy to move and rotate them. Since dielectric properties of fresh fruit are much higher, i.e. heat at faster rate in RF field, than those of tap water, fruit should be immersed in a water solution with properly adjusted ionic conductivity to match that of the fruit to avoid surface burning and core overheating (Ikediala et al., 2002). Fruit should rotate on their axes to reduce the effect of non-uniform RF field throughout the container. In a fruit mover, fruit should not be in constant contact with other fruit or with the walls of container because contact spots concentrate RF energy causing overheating. A fruit mover was designed for RF heating of fresh fruit in a $12 \mathrm{~kW}$ batch type RF heating system (Strayfield Fastran with E-200, Strayfield International Limited, Wokingham, $\mathrm{UK})$.

An appropriate container size was determined based on a desired heating rate when the container was filled with tap water. Assuming negligible energy loss to the surroundings, the rise in the water temperature in the fruit mover as a result of RF heating can be expressed as

$\rho V C_{p} \frac{\Delta T}{\Delta t}=P \eta$

where $\eta$ is the power conversion efficiency (\%) which was about $60 \%$ based on our preliminary tests, $C_{p}$ the specific heat of water at room temperature $\left(4186 \mathrm{~J} /\left(\mathrm{kg}^{\circ} \mathrm{C}\right)\right), \rho$ the density of water $\left(1000 \mathrm{~kg} / \mathrm{m}^{3}\right)$, $V$ the volume of the fruit mover $\left(\mathrm{m}^{3}\right), P$ the displayed power absorbed by water in the RF machine (W), and $\Delta T$ is the water temperature rise $\left({ }^{\circ} \mathrm{C}\right)$ in $\Delta t$ duration (s). For a $12 \mathrm{~kW}$ RF system the maximum coupled power would be $7.2 \mathrm{~kW}$. Based on Eq. (1) and assuming an $8^{\circ} \mathrm{C} / \mathrm{min}$ heating rate, the net volume for water in the fruit mover should be

$$
V_{\max }=\frac{7.2}{(1000 \times 4.186 \times 8 / 60)}=0.0129 \mathrm{~m}^{3}
$$

\subsection{Description of the fruit mover}

The fruit mover consisted of a container $(425 \mathrm{~mm} \times$ $425 \mathrm{~mm} \times 127 \mathrm{~mm}$ ), water jets, a spool, and a transparent top plate (Fig. 1). The container walls and the bottom were made of $10 \mathrm{~mm}$ thick polypropylene. Twelve Teflon water spray nozzles (spiral full cone angle $60^{\circ}$, $91 /$ min discharge, $12.5 \mathrm{~mm}$ diameter) were mounted on the periphery of the container to rotate fruit on their axes and in a circular path. The nozzles were set at fixed angle of $35^{\circ}$ from the wall of the container. To avoid interlocking of fruit at the corners of the container, a polypropylene square skirt with filleted corners was placed in the container. The free-rotating polypropylene spool $(75 \mathrm{~mm}$ in diameter and $60 \mathrm{~mm}$ in height) was placed in the center of the container to keep the fruit away from the center and to facilitate the rotation of the fruit in a specific fixed path along the periphery of the container. A centrifugal pump ( 1 hp, single phase, TEEL Model \# 2PC27, Dayton Electrical Mfg. Co., Niles, IL) circulated water at $40-55 \mathrm{l} / \mathrm{min}$ through a suction pipe connected to one wall of the container and water nozzles. The suction pipe was placed under a perforated $(8 \mathrm{~mm}$ diameter

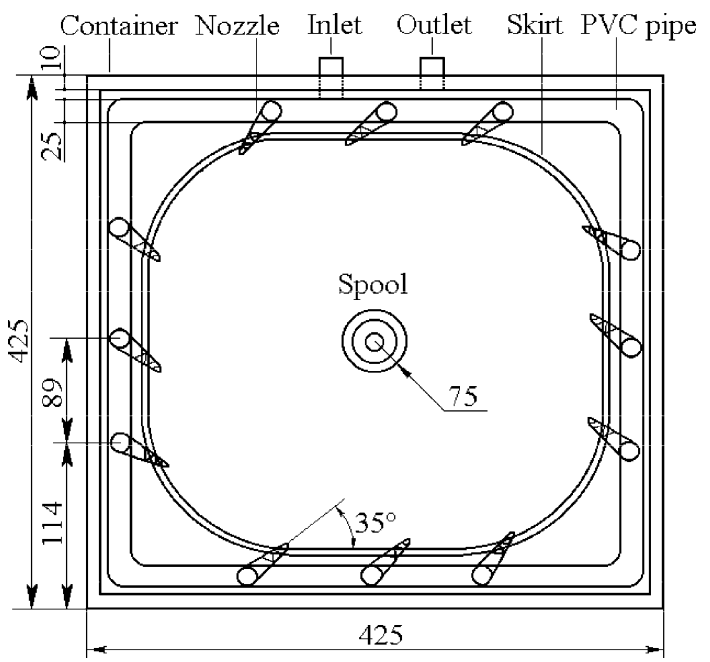

Fig. 1. Schematic diagram showing the top view of the fruit mover (all dimensions are in millimeter). 


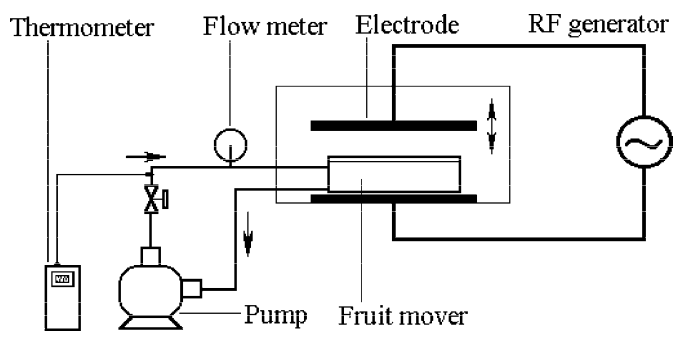

Fig. 2. Schematic diagram of the experimental set-up and water circulation in RF heating system.

holes at spacing of $50 \mathrm{~mm} \times 50 \mathrm{~mm}$ ) polypropylene plate $20 \mathrm{~mm}$ above the bottom of the container to maintain uniform suction pressure, and the water nozzles were mounted $2.5 \mathrm{~cm}$ below the water surface. An $8 \mathrm{~mm}$ thick transparent acrylic sheet was placed on the top of the water to keep the fruit submerged. A pair of baffles (half-circle rods) was glued to the bottom surface of the acrylic top plate to ensure that every fruit spun on its axes after completing about half of the circular motion in the container. To monitor the water temperature during RF heating, a thermocouple (Type-T, $0.8 \mathrm{~mm}$ diameter and $0.8 \mathrm{~s}$ response time, Omega Engineering Ltd., CT) was inserted in the water circulation line. Water flow rate was monitored and controlled with a digital flow meter (Flow Transmitter 3-8503, Signet-Scientific, El Monte, CA) (Fig. 2).

\subsection{Experimental procedures}

\subsubsection{Determination of operating parameters for fruit mover}

The tap water without fruit in the fruit mover was heated first in the RF system to determine the temperature variation. Water temperatures at five locations (four in the corners and one in the center) $1 \mathrm{~cm}$ above the perforated plate and $1 \mathrm{~cm}$ below water surface were measured by thermocouples immediately after RF heating. A comparison of temperature uniformity in the fruit mover was made with and without water circulation. The experiments were repeated three times.

'Naval' oranges (weight $255 \pm 20 \mathrm{~g}$, density $957 \mathrm{~kg} / \mathrm{m}^{3}$ ) and 'Fuji' apples (weight, $245 \pm 15 \mathrm{~g}$; density, $915 \mathrm{~kg} / \mathrm{m}^{3}$ ) were purchased from a local market and stored at $4{ }^{\circ} \mathrm{C}$. Fruit was taken out of cold storage and allowed to equilibrate at room temperature $\left(20^{\circ} \mathrm{C}\right)$ for $12 \mathrm{~h}$. Fruit were randomly selected and each assigned an identification number. Experiments were carried out to determine the correct water circulation rates and fruit batch sizes. Factors important to the selection of correct batch size and water circulation rate were maximum peripheral velocity, axial rotational speed without formation of vortex, and bruising of fruit. The peripheral velocity is defined as linear velocity of the center of fruit moving along the periphery of the container. The axial rotational speed is the number of rotations a fruit made about its own axis per minute while moving along the container periphery. Too fast a movement in the container might cause bruising whereas too slow a movement might be inadequate for uniform heating. Experiments were carried out at water circulation rates of 45,50 , and $55 \mathrm{l} / \mathrm{min}$, and each batch contained seven, eight, and nine fruit.

\subsubsection{Evaluation of $R F$ heating uniformity}

The pilot-scale RF system was used to heat oranges and apples in the fruit mover. Eight oranges or seven apples were placed in the fruit mover and tap water was poured in the container to completely submerge the fruit and the top plate. Based on our preliminary studies, differential heating of apples and water was observed when apples were heated in tap water. Tap water with $0.02 \%$ table salt was appropriate to match the dielectric properties of the water with that of the apple (Wang et al., 2003). The transparent top plate was fixed at $2 \mathrm{~cm}$ below the top edge of the container. The water circulation rate was maintained at 50 and $551 / \mathrm{min}$ for orange and apple, respectively. The gap between the two electrodes (that determined the RF power output) was set to achieve a heating rate of about $5{ }^{\circ} \mathrm{C} / \mathrm{min}$. RF heating was stopped when the water temperature reached $50^{\circ} \mathrm{C}$. Temperature in each individual fruit was immediately measured by the thermocouple at six different locations as shown in Fig. 3. In order to assess improvement in temperature uniformity due to movement and rotation of fruit, oranges and apples were also heated without water circulation (zero water circulation rate) in the RF system as a reference. All experiments were repeated three times. Statistical analysis of data was conducted using PROC GLM procedure of SAS software (SAS Institute, 1989, Cary, NC). The significant difference $(P \leq 0.05)$ was separated by the mean values using 


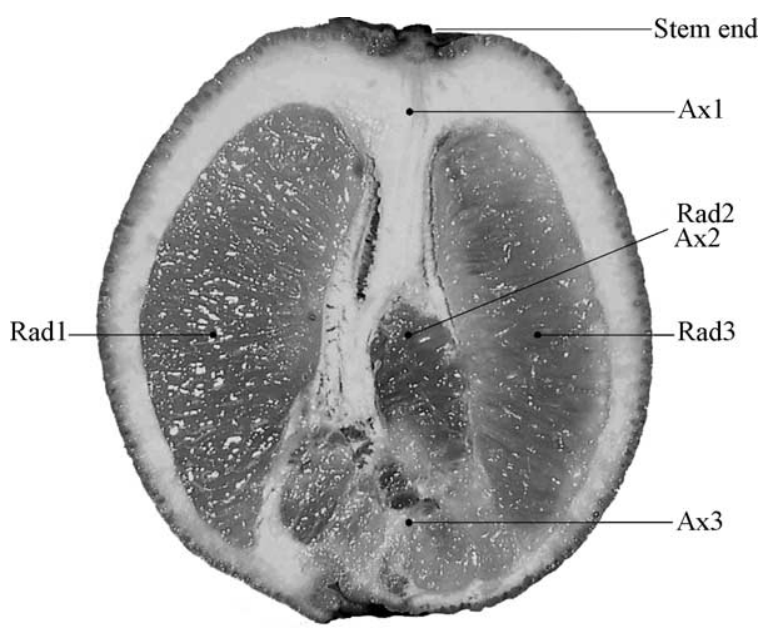

Fig. 3. Temperature measurement locations in an orange.

least significant difference (LSD) and multi pairwise comparisons (Tukey method).

\subsection{Comparison of RF heating of oranges with hot air and hot water heating}

RF heating of $9 \mathrm{~cm}$ diameter navel oranges $(250 \pm$ $10 \mathrm{~g}$ weight) was compared with forced hot air and hot water heating of same size of oranges. In RF heating, seven navel oranges (at $19^{\circ} \mathrm{C}$ ) were placed in the fruit mover filled with $20^{\circ} \mathrm{C}$ tap water. During RF heating, water circulation was reduced until movement of fruit stopped. This was done because the measurement of core temperature was impossible during RF heating with moving or rotating fruit. The core temperature of the orange was measured by a FISO fiber-optic sensor (UMI, FISO Technologies Inc., Saint-Foy, Que., Canada) inserted into an orange through a pinhole. RF heating was done for 5 and $10 \mathrm{~min}$.

The forced air heating of oranges was conducted in a tray drier (UOP8, Armfield Limited, UK) in which air was moved by a fan through a square duct $(28 \mathrm{~cm} \times$ $28 \mathrm{~cm}$ ) that housed a group of electric heating coils. Air speed and temperature were maintained at $1 \mathrm{~m} / \mathrm{s}$ and $53{ }^{\circ} \mathrm{C}$, respectively. The oranges were placed in the middle section of an air heating duct.

The hot water heating of oranges was carried out in a water bath (model ZD, Grant, Cambridge, UK) in which water was circulated at $1 \mathrm{~m} / \mathrm{s}$ and temperature maintained at $53^{\circ} \mathrm{C}$. The core and subsurface $(20 \mathrm{~mm}$ blow surface) temperatures of one orange were measured by two type-T thermocouples.

Data were recorded every $5 \mathrm{~s}$ by a data logger (DL2e, Delta-T Devices Ltd., Cambridge, UK). The temperature distribution inside fruit at different stages of heating was mapped with an infrared imaging camera (ThermaCAM ${ }^{\mathrm{TM}}$ Researcher 2001, accuracy $\pm 2{ }^{\circ} \mathrm{C}$, five picture recordings per seconds, FLIR Systems, Portland, OR). In the hot air and hot water heating trials, fruit samples were taken out after 10, 20, 30, and $40 \mathrm{~min}$ from a batch of oranges for temperature distribution mapping. The heated orange was immediately cut into halves and a thermal image was recorded for one of the cut surface. The temperature distribution in RF heated oranges was mapped for 5 and $10 \mathrm{~min}$ heating.

\section{Results and analyses}

\subsection{Operating parameters for fruit mover}

Table 1 shows the effect of batch size and water circulation rate on rotational characteristics of the fruit. Increasing flow rates increased the axial rotational speed and the linear velocity. However, it was observed that increasing the water circulation rate also increased the tendency of formation of vortex and foaming.

Increasing batch size of fruit reduced both the axial and the peripheral motion of the fruit and increased the tendency of interlocking of fruit and eventual cessation of fruit movement. It was observed that slow rotation increased the chance for the fruit to be in contact with the container walls and top plate for extended times that might cause hot spots on contact surfaces during RF heating. On the other hand, we observed that reduced batch size caused non-uniformly distributed load (varying fruit-to-fruit distance) inside the RF field, and this in turn increased the variability in heating rates of individual fruit. Eight naval oranges per batch (fruit volume was $12.5 \%$ of total volume of fruit and water) in the container met both requirements of uniformly distributed RF load and three-dimensional rotation of the fruit in the RF field (Table 1). High water circulation rate imparted kinetic energy to fruit and caused frequent fruit to fruit collision and striking of fruit to the periphery of the container, which might cause bruising of fruit. Optimum 
Table 1

Effect of water circulation rate and batch size on the linear velocity, and axial and peripheral rotation speed of oranges and apples

\begin{tabular}{|c|c|c|c|c|c|c|c|}
\hline \multirow[t]{3}{*}{ Fruit } & \multirow{3}{*}{$\begin{array}{l}\text { Water circulation } \\
\text { rate }(1 / \mathrm{min})\end{array}$} & \multicolumn{6}{|c|}{ Fruit rotation $(\mathrm{rpm})$ and linear velocity (in parenthesis, $\mathrm{m} / \mathrm{s}$ ) at batch size of } \\
\hline & & \multicolumn{2}{|l|}{ Seven } & \multicolumn{2}{|l|}{ Eight } & \multicolumn{2}{|l|}{ Nine } \\
\hline & & Peripheral & Axial & Peripheral & Axial & Peripheral & Axial \\
\hline \multirow[t]{3}{*}{ Orange } & 45 & $20(0.28)$ & 26 & $16(0.23)$ & 26 & $13(0.19)$ & 18 \\
\hline & 50 & $23(0.32)$ & 32 & $21(0.30)$ & 30 & $17(0.24)$ & 24 \\
\hline & 55 & $26(0.37)^{\mathrm{a}}$ & 35 & $24(0.34)^{\mathrm{a}}$ & 34 & $20(0.29)$ & 26 \\
\hline \multirow[t]{3}{*}{ Apple } & 45 & $12(0.12)$ & 13 & $0^{\mathrm{b}}$ & 0 & 0 & 0 \\
\hline & 50 & $14(0.20)$ & 19 & $10(0.14)$ & 16 & 0 & 0 \\
\hline & 55 & $17(0.24)$ & 22 & $13(0.19)$ & 17 & $10(0.14)$ & 13 \\
\hline
\end{tabular}

\footnotetext{
${ }^{\text {a }}$ Indicates overflow and vortex forming.
}

b Zero indicates the cessation of rotation.

flow rate was $501 / \mathrm{min}$ for eight oranges (the water jet velocity was $9 \mathrm{~m} / \mathrm{s}$ at the end of nozzle tip) without overflowing of water from the container edges. At this flow rate the linear velocity of the fruit center was $0.30 \mathrm{~m} / \mathrm{s}$ in the mover. It was observed that axial rotation was higher than the peripheral rotation of oranges in the mover (Table 1). This is desirable in view of RF heating of a large spherical shaped commodity because every part of a large fruit needs to be exposed to RF field for uniform heating. The axial rotation decreased with increasing batch size because of less free space available for movement of fruit in the container.

Table 1 shows that apples moved and spun at a slower speed compared with oranges for the same batch size and water circulation rate. With nine apples in the container, interlocking was frequently observed even at high water circulation rates. Interlocking and cessation of axial rotation of fruit were observed with eight apples at the water circulation rate of $45 \mathrm{l} / \mathrm{min}$. The rotational ability of fruit was hampered by non-spherical shape and low density of 'Fuji' apples even at higher circulation rates. Therefore, seven apples per batch (fruit volume was $11 \%$ of total volume of fruit and water) was found to be appropriate to obtain desired rotational characteristics. A water flow rate at $551 / \mathrm{min}$ (peripheral velocity of fruit was $0.24 \mathrm{~m} / \mathrm{s}$, and water jet velocity was $10 \mathrm{~m} / \mathrm{s}$ at end of the nozzle tip) was found to be a suitable flow rate that avoided bruising and vortex forming and provided desired rotational characteristics.

Without water circulation, the mean water temperature at the 10 locations was $45.7^{\circ} \mathrm{C}$ with a $9.5^{\circ} \mathrm{C}$ standard deviation. The average temperature $\left(54.66{ }^{\circ} \mathrm{C}\right)$ of all the measured points at the top layer $(1 \mathrm{~cm}$ below water surface) was significantly higher than the average temperature $\left(36.78^{\circ} \mathrm{C}\right)$ at points those at the bottom layer $(1 \mathrm{~cm}$ above the perforated plate). The maximum differences among five locations were 3.4 and $2.7^{\circ} \mathrm{C}$ for top and bottom layers, respectively. With water circulation, the temperature uniformity was significantly improved as the mean water temperature at the 10 locations in the container was $49.7{ }^{\circ} \mathrm{C}$ with only $0.4{ }^{\circ} \mathrm{C}$ standard deviation, and there was no significant difference $(P>0.05)$ found in temperatures between top and bottom layers.

\subsection{Heating uniformity of naval oranges}

Fig. 4 shows temperature variations in RF heating of eight oranges without (A) and with (B) water circulation. The average heating rate for oranges was approximately $5^{\circ} \mathrm{C} / \mathrm{min}$ at the coupled RF power of $7.0 \mathrm{~kW}$. Without water circulation, the mean temperature of an individual orange after RF heating varied from 48.7 to $60.2^{\circ} \mathrm{C}$ with the standard deviation in each fruit varying from 2.5 to $4.9^{\circ} \mathrm{C}$ (Fig. 4A). The mean temperature of eight fruit was $53.6^{\circ} \mathrm{C}$ with an overall $4.8^{\circ} \mathrm{C}$ standard deviation. The mean temperatures were significantly different $(P<0.05)$ among different oranges. With water circulation, the mean temperature at different locations in an individual orange after RF heating varied from 49.2 to $52.8^{\circ} \mathrm{C}$ with the standard deviation varying from 0.3 to $2.8^{\circ} \mathrm{C}$ (Fig. 4B). The mean temperature among eight oranges was $51.6^{\circ} \mathrm{C}$ with $2{ }^{\circ} \mathrm{C}$ standard deviation and there was no significant difference in temperature $(P>0.05)$ among 


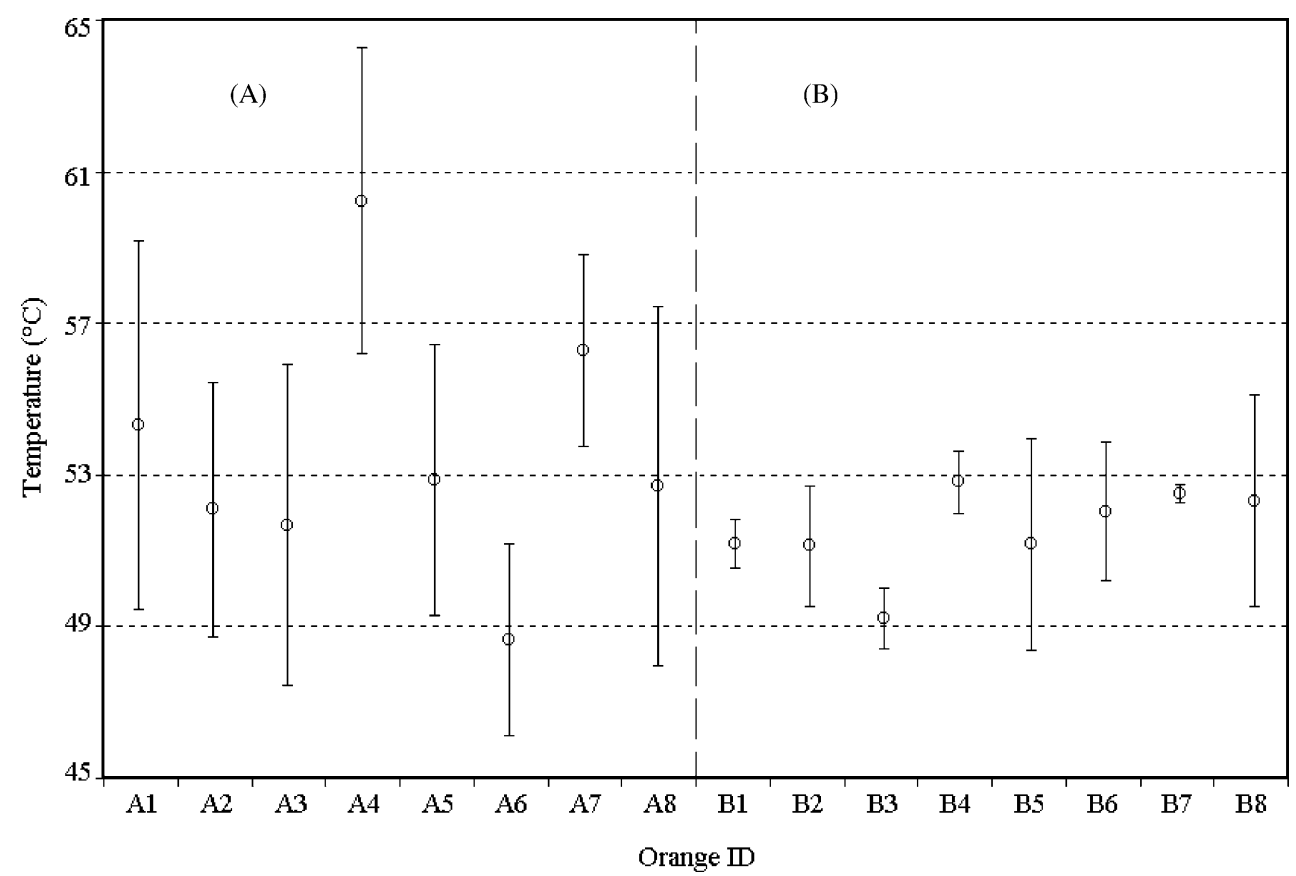

Fig. 4. Temperature variations (mean and standard deviation values over six locations) in eight oranges heated by RF for 5.5 min without (A) and with (B) water circulation from $20^{\circ} \mathrm{C}$ initial temperature of fruit.

oranges and within an orange. Therefore, with the proper movement and rotation, the variations of temperature among oranges and within individual fruit were significantly reduced. As shown in Fig. 4 with and without rotation of oranges during RF heating, the temperature variation was more prominent among oranges than within an orange. This variation might have been the result of natural variations in oranges such as different physical/chemical properties and internal structures. We have observed consistent hot spots on the naval end (Ax3 in Fig. 3) of an orange probably because of dense material at this end. The mean temperature of oranges was slightly higher than the temperature of water in the container probably because the dielectric loss factor of tap water was lower than that of oranges.

Fig. 5 shows temperature distribution in an orange as measured by an infrared thermal imaging camera immediately after the oranges were subjected to $\mathrm{RF}$ heating for $5.5 \mathrm{~min}$. Without rotation, certain areas of the fruit were overheated (Fig 5A). Overheating was observed at the points where fruit surface was in contact with the top plate, which was placed above the fruit to keep them submerged in water. The non-uniform heating was eliminated by movement and rotation of oranges in RF field (Fig. 5B).

\subsection{Heating uniformity of Fuji apples}

Without water circulation, the mean temperature of individual apples varied from 54.4 to $70.0^{\circ} \mathrm{C}$ with the standard deviation varying from 1.0 to $9.6^{\circ} \mathrm{C}$ (Fig. 6A). The mean overall temperature of apples in a sample was $60.4{ }^{\circ} \mathrm{C}$ with $4.3^{\circ} \mathrm{C}$ standard deviation and the mean temperatures of individual apples were significantly different $(P<0.05)$. With water circulation, the mean temperature of the individual RF heated apple varied from 49.2 to $53.0^{\circ} \mathrm{C}$ with the standard deviation varying from 0.6 to $3.1^{\circ} \mathrm{C}$ (Table 2; Fig. 6B). The mean temperature over seven apples was $51.1^{\circ} \mathrm{C}$ with an overall $2.2{ }^{\circ} \mathrm{C}$ standard deviation. There was no significant difference $(P>0.05)$ in mean temperatures of apples except between apple \#3 and 5 (Table 2). Similar to observations with oranges, rotation and movement of apples in RF field reduced temperature variation significantly among the fruit and 


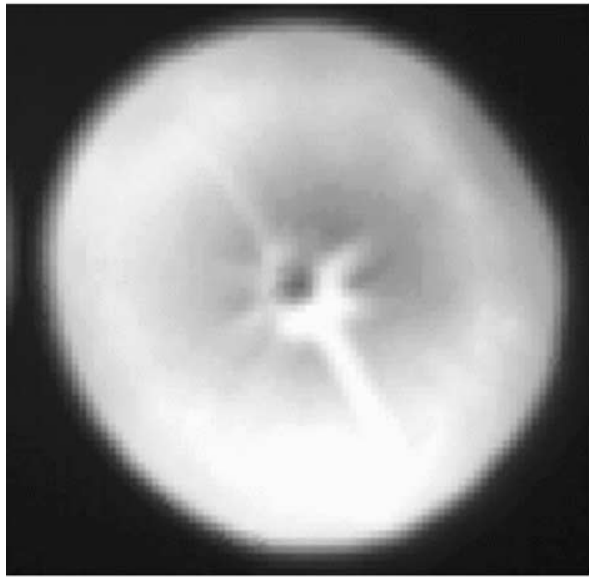

(A) Without rotation

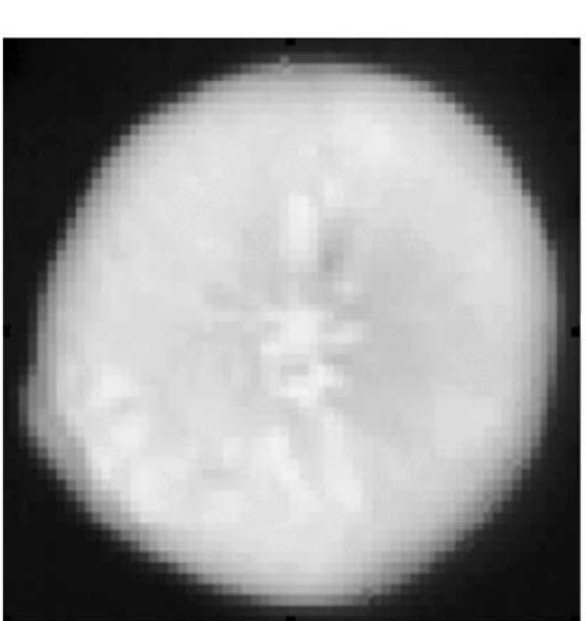

(B) With rotation

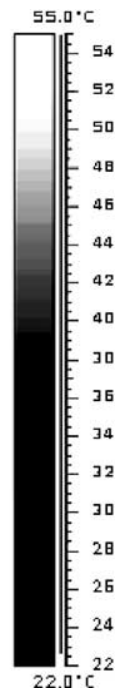

Fig. 5. Thermal images showing temperature distributions in oranges when subjected to RF heating for 5.5 min with or without rotation of oranges in the container (starting fruit core temperature, $20^{\circ} \mathrm{C}$ ).

within each individual fruit (Fig. 6). Table 2 shows that the temperatures at stem side $(\mathrm{Ax} 1)$ and bottom side of fruit $(\mathrm{Ax} 3)$ were significantly $(P<0.05)$ high compared with other locations on an apple. The path along this axis was the shortest route for RF energy to pass. The consistent hot spots on these two ends suggests that the shape of a fruit highly influences the temperature uniformity within a fruit.

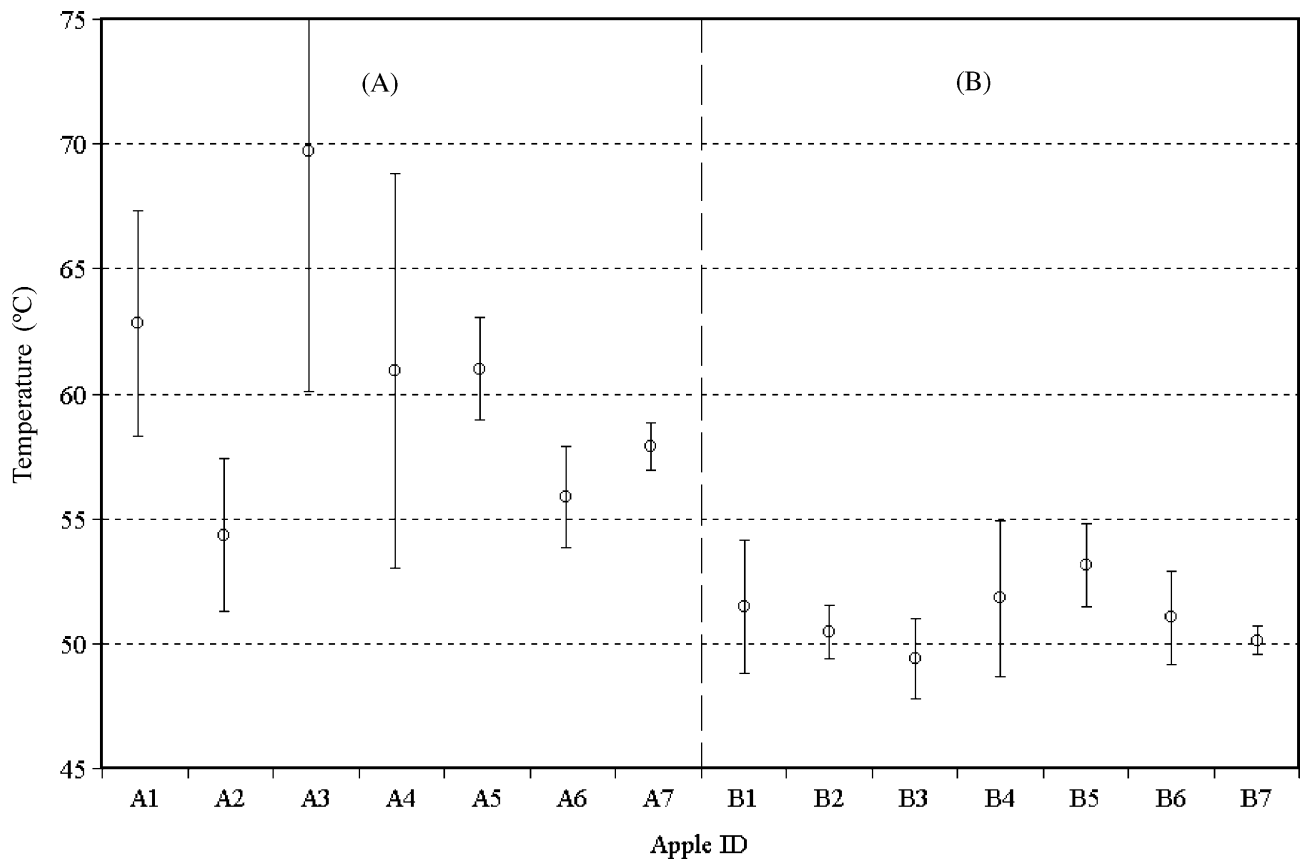

Fig. 6. Temperature variations (mean and standard deviation values over six locations) in seven apples heated by RF for 6 min without (A) and with (B) water circulation from $20^{\circ} \mathrm{C}$ initial temperature of fruit. 
Table 2

Final temperature, mean and standard deviation (STD) values for six locations in an individual apple and among seven apples heated by $\mathrm{RF}$ for $5.5 \mathrm{~min}$. from $20^{\circ} \mathrm{C}$ initial fruit temperature

\begin{tabular}{|c|c|c|c|c|c|c|c|c|}
\hline \multirow[t]{2}{*}{ Fruit } & \multicolumn{8}{|c|}{ Temperature $\left({ }^{\circ} \mathrm{C}\right)$} \\
\hline & Rad1 & $\operatorname{Rad} 2$ & $\operatorname{Rad} 3$ & Ax1 & $\mathrm{Ax} 2$ & Ax3 & Mean & STD \\
\hline 1 & 49.6 & 48.1 & 49.5 & 53.6 & 53.7 & 54.2 & 51.5 & 2.67 \\
\hline 2 & 50.8 & 49.6 & 51.2 & 51.9 & 50.4 & 48.9 & 50.5 & 1.09 \\
\hline 3 & 48.9 & 48.0 & 47.4 & 51.6 & 50.6 & 50.0 & $49.4^{*}$ & 1.60 \\
\hline 4 & 49.8 & 48.9 & 48.6 & 55.7 & 53.2 & 54.7 & 51.8 & 3.11 \\
\hline 5 & 53.1 & 51.1 & 51.3 & 54.1 & 54.2 & 55.2 & $53.2^{*}$ & 1.66 \\
\hline 6 & 49.1 & 49.2 & 50.3 & 53.8 & 51.4 & 52.5 & 51.1 & 1.87 \\
\hline 7 & 51.0 & 49.5 & 49.5 & 50.1 & 50.3 & 50.4 & 50.1 & 0.58 \\
\hline Mean & $50.3 \mathrm{ac}^{* *}$ & $49.2 \mathrm{a}$ & $49.7 \mathrm{a}$ & $53.0 \mathrm{~b}$ & $52.0 \mathrm{ab}$ & $52.3 \mathrm{bc}$ & 51.1 & \\
\hline STD & 1.46 & 1.05 & 1.40 & 1.87 & 1.68 & 2.53 & & 2.15 \\
\hline
\end{tabular}

* Means in column with $\left(^{*}\right)$ sign are significantly different $(P<0.05)$.

** Means in row with different letters are significantly different $(P<0.05)$.

\subsection{Comparison of RF heating of oranges with hot air and hot water heating}

Fig. 7 shows experimental time-temperature histories for oranges (fruit diameter, $9 \mathrm{~cm}$ ) when subjected to hot air, hot water and RF heating. It took about 66 and $173 \mathrm{~min}$ for core temperature to reach $50^{\circ} \mathrm{C}$ in hot water and hot air heating, respectively. In RF heating, core temperature increased linearly with the process time and heated at a rate varying from 3 to $5{ }^{\circ} \mathrm{C} / \mathrm{min}$ from fruit to fruit. Please note that in the above RF heating tests, the fruit was stationary in water to allow monitoring of temperature with fiber-optic sensors, which was different from the tests for RF heating uniformity assessment where fruit were moving and rotating in water-filled container. There appeared to be no marked temperature difference between core and subsurface with respect to process time during the RF heating while the temperature difference between subsurface $(2 \mathrm{~cm}$ deep) and core was fairly

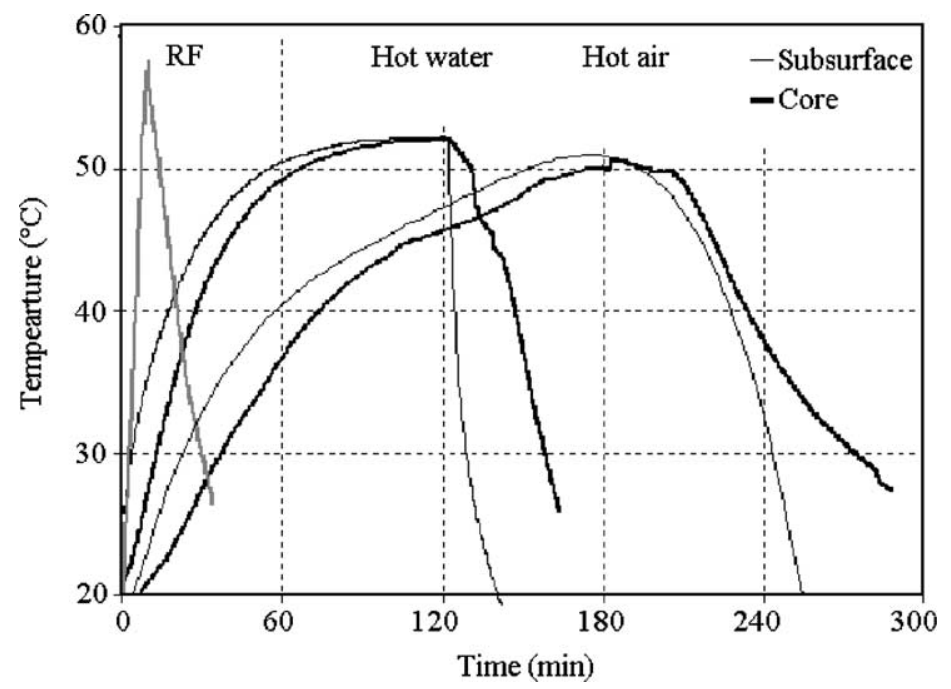

Fig. 7. Experimental heating and cooling curves for orange $(9 \mathrm{~cm}$ diameter) center and subsurface ( $2 \mathrm{~cm}$ deep) when subjected to forced hot air (air temperature, $53^{\circ} \mathrm{C}$; air speed, $1 \mathrm{~m} / \mathrm{s}$ ), hot water $\left(53^{\circ} \mathrm{C}\right.$ ) and radio frequency (RF: $\left.27.12 \mathrm{MHz}\right)$ treatments. 


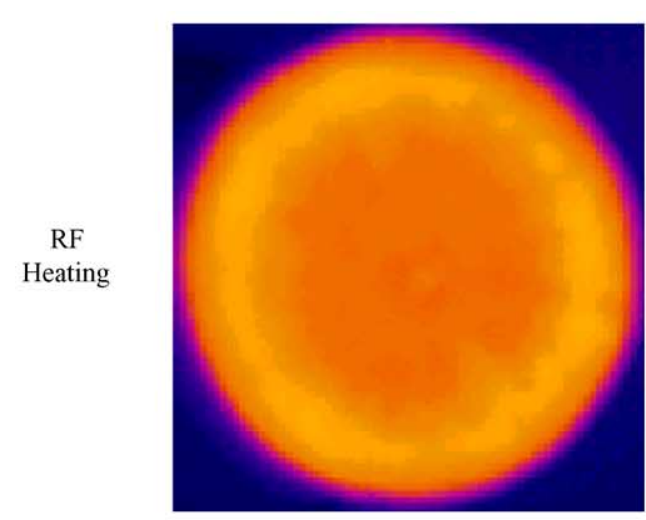

After 5 min

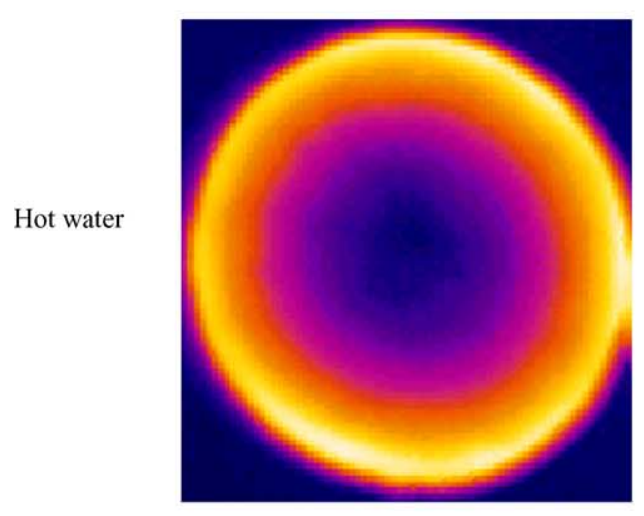

After $10 \mathrm{~min}$

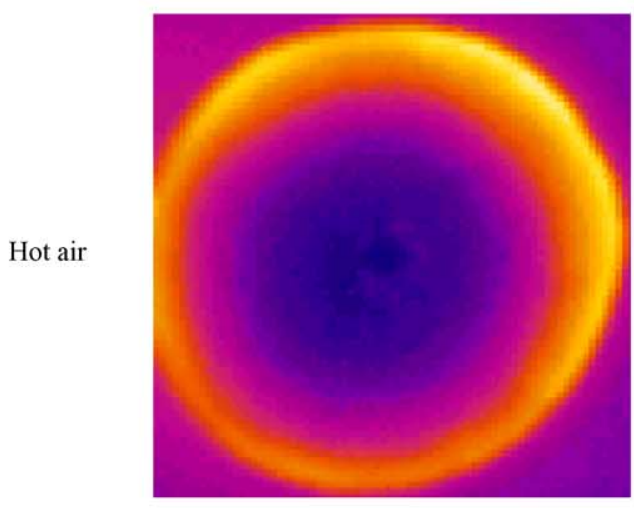

After $10 \mathrm{~min}$

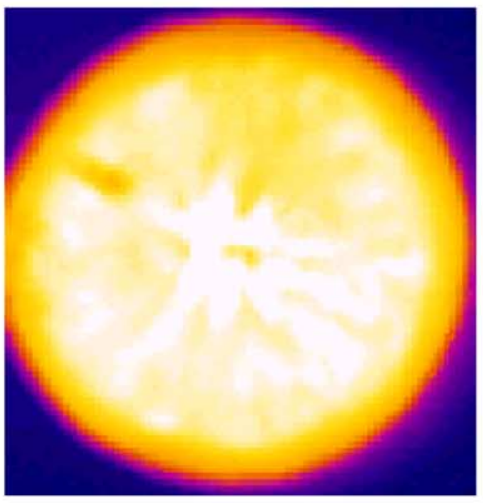

After $10 \mathrm{~min}$

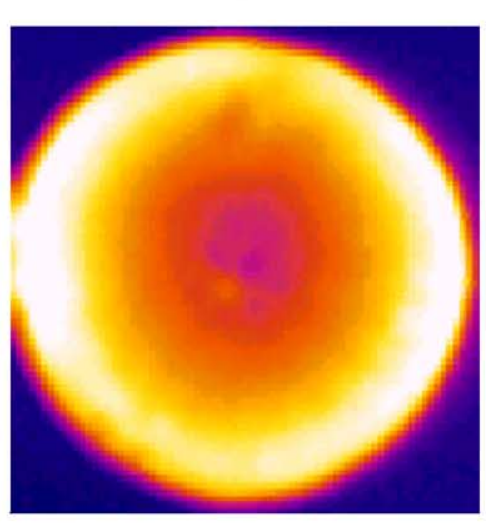

After $20 \mathrm{~min}$

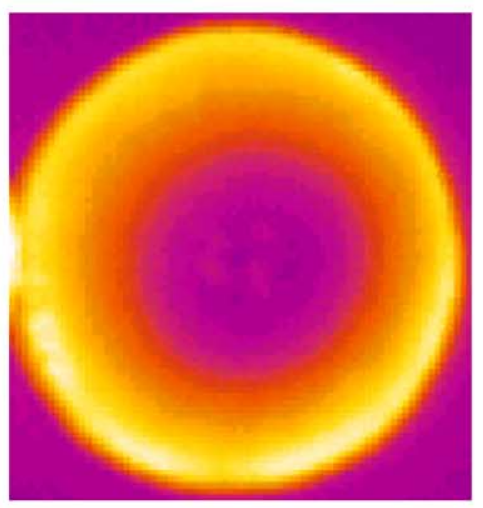

After $20 \mathrm{~min}$
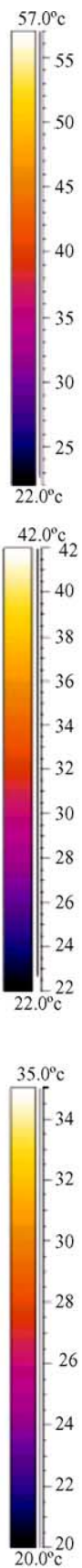

Fig. 8. Thermal images showing temperature distributions in oranges $(9 \mathrm{~cm}$ diameter $)$ when subjected to RF heating for 5 and $10 \mathrm{~min}$, to hot water and hot air heating at $53{ }^{\circ} \mathrm{C}$ for 10 and $20 \mathrm{~min}$ from $20^{\circ} \mathrm{C}$ initial fruit temperature. 
Table 3

Core temperature of oranges measured by thermal imaging (T/I) and thermocouple (T/C) in hot water, hot air and RF heating

\begin{tabular}{|c|c|c|c|c|c|c|}
\hline \multirow{2}{*}{$\begin{array}{l}\text { Heating time } \\
(\min )\end{array}$} & \multicolumn{2}{|c|}{ Hot water $\left({ }^{\circ} \mathrm{C}\right)$} & \multicolumn{2}{|c|}{ Hot air $\left({ }^{\circ} \mathrm{C}\right)$} & \multicolumn{2}{|c|}{$\mathrm{RF}\left({ }^{\circ} \mathrm{C}\right)$} \\
\hline & $\mathrm{T} / \mathrm{I}$ & $\mathrm{T} / \mathrm{C}$ & $\mathrm{T} / \mathrm{I}$ & $\mathrm{T} / \mathrm{C}$ & $\mathrm{T} / \mathrm{I}$ & $\mathrm{T} / \mathrm{C}$ \\
\hline 0 & 18 & 20.2 & 18 & 19.8 & 18 & 20.1 \\
\hline 5 & - & - & - & - & 36 & 38.6 \\
\hline 10 & 25 & 26.9 & 19 & 20.2 & 56 & 57.4 \\
\hline 20 & 33 & 35.2 & 23 & 23.9 & - & - \\
\hline 30 & 39 & 41.1 & 25 & 27.3 & - & - \\
\hline 40 & 43 & 45.0 & 28 & 30.8 & - & - \\
\hline
\end{tabular}

large with hot water and hot air (Fig. 7). In hot air treatment, the temperature difference persisted even after $3 \mathrm{~h}$ of heating. RF heating was approximately 8.8 and 23 times faster compared with hot water and air, respectively, as it took only $7.5 \mathrm{~min}$ to heat from 20 to $50^{\circ} \mathrm{C}$. RF treatment has particular advantages over conventional heating in treating large fruit.

Fig. 8 illustrates the temperature distributions inside an orange measured with the infrared thermal imaging technique when subjected to RF heating for 5 and $10 \mathrm{~min}$, and to hot water and hot air heating at $53^{\circ} \mathrm{C}$ for 10 and $20 \mathrm{~min}$ (initial fruit temperature, $20^{\circ} \mathrm{C}$ ). Ten minutes RF heating time was chosen to compare with other methods of heating for the same duration. RF heating resulted in fairly uniform temperatures over the entire orange and achieved the target temperature in a short time. With the hot water and hot air treatments, a large temperature gradient was observed from the surface to the core. Table 3 shows the comparison of measured temperature by an infrared camera and by a thermocouple when oranges were subjected to $\mathrm{RF}$, hot air and hot water heating. Taking into account the initial temperatures and elapsed time before the image was taken, a good agreement was obtained for both measurement methods. In general, the RF heating was more uniform and faster than hot water or hot air treatments.

\subsection{Design considerations for industrial scale fruit mover}

The results of this study suggest that moving and rotating a fruit can overcome the obstacle of a non-uniform RF field and irregular geometry of the fruit. It is, therefore, possible to develop a RF heat treatment protocol to control insect pests in large fruit. Because the medium (water) was $85-90 \%$ of the total RF heat load in our study, a major challenge in developing a continuous process using this concept relies on recovery of heat from the medium for energy savings. RF heating may be used for preheated fruit (preheating to non-damaging temperature by conventional method) to maximize energy efficiency and throughput. An industrial scale fruit mover should have a high ratio of fruit volume to total volume of heating load. For industrial scale RF heating systems, the rotation and the movement of fruit may be accomplished in a flume that may be a part of the applicator. In a flume, a series of baffles can be placed in a staggered fashion to provide a zigzag path for fruit. The top covering plate may have corrugations to facilitate axial rotations of fruit. The water nozzles may be mounted on the side walls to propel the fruit. The flume may have a false perforated bottom through which water can be pumped out so that the buoyancy force on the fruit can be reduced and facilitate movement of fruit. The arrangement of the perforations in the false bottom can be made in such a fashion that the suction pressure is uniform over the length and width of the bottom.

\section{Conclusions}

RF treatments had an advantage of fast heating over conventional hot air and hot water heating for large fruit. The fruit mover was capable of rotating the fruit on their axes and moving them in the RF field. The rotational ability of the fruit was greatly influenced by the batch size and the water circulation rate, which were determined experimentally to obtain desired rotational characteristics. For naval oranges, $12.5 \%$ fruit volume (based on total volume of water and fruit) with a $501 / \mathrm{min}$ flow rate corresponding to $9 \mathrm{~m} / \mathrm{s}$ water jet velocity at a point of exit from the nozzles were found to be best to obtain desired movement of the fruit. Similarly for 'Fuji' apples $11.0 \%$ fruit volume and $10 \mathrm{~m} / \mathrm{s}$ water jet velocity were found to be best. The rotation and movement of fruit minimized the adverse effect of the non-uniform RF field and the irregular geometry of the fruit and improved 
RF heating uniformity. Fruit geometry was found to influence the heating pattern. Apples with typical geometry (oval and dimples on ends) showed more variation in temperature within a fruit than oranges, which are almost spherical. Oranges were heated with less than $\pm 2{ }^{\circ} \mathrm{C}$ variation within an orange and $\pm 3{ }^{\circ} \mathrm{C}$ temperature variation among oranges. Apples were heated with less than $\pm 2.5^{\circ} \mathrm{C}$ variation within an apple and $\pm 3.5^{\circ} \mathrm{C}$ temperature variation among apples.

\section{Acknowledgements}

This research was conducted by the Washington State University Agricultural Research Center and was supported by grants from BARD (US-3276-01) and USDA-IFAFS (00-52103-9656). We thank Mr. Wayne Dewitt of Washington State University for assisting in fabrication of the fruit mover.

\section{References}

Burditt, A.K.J., 1982. Food irradiation as a quarantine treatment of fruits. Food Technol. November, 51-54-58-60, 62.

Calkins, C.O., 1993. Future directions in control of the Caribbean fruit fly (Diptera: Tephritidae). Flo. Entomol. 76, 263-270.

Frings, H., 1952. Factors determining the effects of radio frequency electromagnetic fields and materials they infest. J. Econ. Entomol. 45, 396-408.

Gazit, Y., Rossler, Y., Wang, S., Tang, J., Lurie, S., 2004. Thermal death kinetics of egg and third-instar Mediterranean fruit fly (Diptera: Tephritidae). Stored Product Quarantine Entomol. in press.

Hallman, G.J., Sharp, J.L., 1994. Radio frequency heat treatments. In: Sharp, J.L., Hallman, G.J. (Eds.), Quarantine Treatments for Pests of Food Plants. Westview Press, San Francisco, CA, pp. $165-170$.

Hansen, J., 1992. Heating curve models of quarantine treatments against insect pests. J. Econ. Entomol. 85, 1846-1854.

Hansen, J.D., Drake, S.R., Moffitt, H.R., Robertson, J.L., Albano, D.J., Heidt, M.L., 2000. A two-component quarantine treatment for postharvest control of codling moth on apple cultivars intended for export to Japan and Korea. Hort. Technol. 10, 186-194.

Hatton, T.T., Cubbredge, R.H., Risse, L.A., Spalding, D.H., Windeguth, D.L., Chew, V., 1984. Phytotoxic responses of Florida grapefruit to low-dose irradiation. J. Am. Soc. Hortic. Sci. 109, 607-610.
Headlee, T.J., Burdette, R.C., 1929. Some facts relative to the effect of high frequency radio waves on insect activity. J. N. Y. Entomol. Soc. 37, 59-64.

Ikediala, J.N., Tang, J., Hansen, J., Drake, S.R., Wang, S., 2002. Quarantine treatment of fruits using radio frequency energy and an ionic-water-immersion technique. Postharvest Biol. Technol. $24,25-37$.

Lurie, S., 1998. Postharvest heat treatments of horticultural crops: commodity responses. Postharvest Biol. Technol. 14, 257-269.

Nelson, S.O., Payne, J.A., 1982. RF dielectric heating for pecan weevil control. Trans. ASAE 31, 456-458.

Schiffman-Nadel, M., Chalutz, E., Wax, J., Dagan, M., 1975. Reduction of chilling injury in grapefruit by thiabendazole and benomyl during long term storage. J. Am. Soc. Hortic. Sci. 100, 276-276.

Schiffman-Nadel, M., Chalutz, E., Wax, J., Lattar, F.S., 1972. Reduction of pitting of grapefruit by thiabendazole during long term cold storage. HortScience 7, 394-394.

Sharp, J.L., Gaffney, J.J., Moss, J.I., Gould, W.P., 1991. Hot-air treatment device for quarantine research. J. Econ. Entomol. 84, 520-527.

Shellie, K.C., Firko, M.J., Mangan, R.L., 1992. Phytotoxic response of 'Dancy' tangerine to high-temperature moist forced-air treatment for fruit fly disinfestation. J. Am. Soc. Hort. Sci. 118, 481-485.

Shellie, K.C., Mangan, R.L., 1993. Disinfestation of subtropical commodities with hot forced air. Acta Hortic. 343, 367-370.

Shellie, K.C., Mangan, R.L., 1995. Heating rate and tolerance of naturally degreened 'Dancy' tangerine to high-temperature, forced air for fruit fly disinfestation. HortTechnol. 5, 40-43.

Shellie, K.C., Mangan, R.L., 1998. Tolerance of navel orange to heat treatments for disinfestation of Mexican fruit fly. J. Am. Soc. Hort. Sci. 123, 288-293.

Soderstrom, E.L., Brandl, D.G., Mackey, B.E., 1996. High temperature alone and combined with controlled atmospheres for control of diapausing codling moth (Lepidoptera: Tortricidae) in walnuts. J. Econ. Entomol. 89, 144-147.

Tang, J., Ikediala, J.N., Wang, S., Hansen, J., Cavalieri, R., 2000. High-temperature-short-time thermal quarantine methods. Postharvest Biol. Technol. 21, 129-145.

UNEP. United Nations Environmental Programme, 1992. In: Proceedings of the Fourth Meeting of the parties to the Montreal Protocol on Substances that Deplete the Ozone Layer. Copenhagen, Nairobi, Kenya, 23-35 November 1992.

[USDA] United States Department of Agriculture, 2001. Agricultural Statistics. Washington, DC.

[USEPA] United States Environmental Protection Agency, 1998. Reregistration Eligibility Decision. Aluminum and Magnesium Phosphide. Cases 0025 and 0645. Office of Pesticide Programs, Special Review and Reregistration Division.

Wang, S., Ikediala, J.N., Tang, J., Hansen, J.D., Mitcham, E., Mao, R., Swanson, B., 2001a. Radio frequency treatments to control codling moth in in-shell walnuts. Postharvest Biol. Technol. 22, 29-38.

Wang, S., Tang, J., Cavalieri, R.P., 2001b. Modeling fruit internal heating rates for hot air and hot water treatments. Postharvest Biol. Technol. 22, 257-270. 
Wang, S., Tang, J., Johnson, J.A., Mitcham, E., Hansen, J.D., Cavalieri, R., Bower, J., Biasi, B., 2002. Process protocols based on radio frequency energy to control field and storage pests in in-shell walnuts. Postharvest Biol. Technol. 26, 265273.
Wang, S., Tang, J., Johnson, J.A., Mitcham, E., Hansen, J.D., Hallman, G., Drake, S.R., Wang, Y., 2003. Dielectric properties of fruits and insect pests as related to radio frequency and microwave treatments. Biosyst. Eng. 85, 201212. 